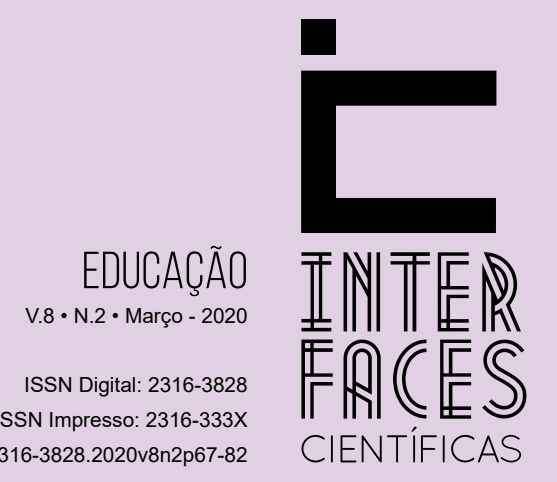

DOI: $10.17564 / 2316-3828.2020 v 8 n 2 p 67-82$

\section{VIOLÊNCIA CONTRA MULHERES NAS REDES SOCIAIS: O CASO DE ELAINE PEREZ CAPARRÓZ}

VIOLENCE AGAINST WOMEN IN SOCIAL NETWORKS: THE CASE ELAINE PEREZ CAPARRÓZ

\section{VIOLENCIA CONTRA LAS MUJERES EN LAS REDES SOCIALES: EL CASO DE ELAINE PÉREZ CAPARRÓZ}

Telma Brito Rocha ${ }^{1}$

Cleyton Williams G. S. Brandão ${ }^{2}$

\section{DOSSIÊ:}

"CORPO, GENNERO E SEXUALIDADE NA CIBERCULTURA: MODOS DE CONHECER, PRÁTICAS DE SOCIABILIDADE E REDES EDUCATIVAS"

\section{RESUMO}

A violência configura-se como um problema para a sociedade brasileira. A expressão dessa problemática demonstra a ausência do diálogo e de uma visão crítica, seja por parte de quem a assiste ou de quem a vivencia. Trata-se de um fenômeno multifacetado, que não atinge apenas a integridade física, mas também a integridade psíquica, emocional e simbólica de mulheres, seja na "vida on-line" ou "off-line”. A análise das causas e das relações que geram condutas violentas impõe alguns desafios aos pesquisadores: demanda tanto o reconhecimento das especificidades das situações nesta sociedade em rede, como a compreensão de processos mais abrangentes que produzem a violência. Nessa contextura, por meio da análise de conteúdo proposta por Bardin (2011), capturou-se prints com os comentários dos internautas em postagens no Facebook e inferiu-se reflexões acerca das intencionalidades ofensivas dos sujeitos em questão. Buscou-se levantar os discursos de ódio direcionados às mulheres na rede on-line, a fim de conhecer os conceitos de violência e a legislação brasileira para os crimes na internet, discutindo medidas educativas dentro do ensino básico brasileiro para prevenção desse problema na atualidade. No decorrer da pesquisa, foram analisados oitenta e três prints de comentários de seis publicações distintas e, nesse escrito, apresentar-se-á quatro figuras, contendo comentários de um caso, que perpassam por questões de machismo, culpabilização da vítima, difamação, discriminação etária e "comportamento ideal feminino". Assim, entende-se que a educação de base deve ser transformadora, a fim de formar cidadãos críticos e reflexivos acerca do seu papel social.

\section{PALAVRAS-CHAVE}

Violência. Mulheres. Redes Sociais. Elaine Perez Caparróz. 


\section{ABSTRACT}

Violence is a problem for Brazilian society. The expression of this problem demonstrates the absence of dialogue and a critical view, either by those who assist it or by those who experience it. It is a multifaceted phenomenon that not only affects the physical integrity, but also the psychic, emotional and symbolic integrity of women, whether in "online" or "offline" life. The analysis of the causes and relationships that generate violent behavior poses some challenges for researchers: it demands both the recognition of the specificities of situations in this network society, and the comprehension of broader processes that produce violence. In this context, through the content analysis proposed by Bardin (2011), we captured prints with the comments of Internet users in Facebook posts and inferred reflections about the offensive intentionalities of the subjects in question. We sought to raise hate speeches directed at women in the online network, in order to know the concepts of violence and the Brazilian legislation for Internet crimes, discussing educational measures within the Brazilian elementary school to prevent this problem today. In the course of the research, eighty-three commentary prints from six different publications were analyzed and, in this writing, four figures will be presented containing comments of a case, which are related to machismo, blaming the victim, defamation, age discrimination. and "female ideal behavior". Thus, it is understood that basic education must be transformative in order to form critical and reflective citizens about their social role.

\section{KEYWORDS}

Violence. Women. Social Networks. Elaine Perez Caparróz.

\section{RESUMEN}

La violencia es un problema para la sociedad brasileña. La expresión de este problema demuestra la ausencia de diálogo y una visión crítica, ya sea por quienes lo ayudan o por quienes lo experimentan. Es un fenómeno multifacético que no solo afecta la integridad física, sino también la integridad psíquica, emocional y simbólica de las mujeres, ya sea en la vida "en línea” o “fuera de línea”. El análisis de las causas y las relaciones que generan un comportamiento violento plantea algunos desafíos para los investigadores: exige tanto el reconocimiento de las especificidades de las situaciones en esta sociedad de red como la comprensión de procesos más amplios que producen violencia. En este contexto, a través del análisis de contenido propuesto por Bardin (2011), capturamos impresiones con los comentarios de los usuarios de Internet en las publicaciones de Facebook e inferimos reflexiones sobre las intenciones ofensivas de los sujetos en cuestión. Intentamos generar discursos de odio dirigidos a las mujeres en la red en línea, para conocer los conceptos de violencia y la legislación brasileña para delitos en Internet, discutiendo medidas educativas dentro de la escuela primaria brasileña para prevenir este problema hoy. En el curso de la investigación, se analizaron ochenta y tres 
impresiones de comentarios de seis publicaciones diferentes y, en este escrito, se presentarán cuatro figuras que contienen comentarios de un caso, que están relacionados con el machismo, culpar a la víctima, difamación, discriminación por edad. y “comportamiento ideal femenino”. Por lo tanto, se entiende que la educación básica debe ser transformadora para formar ciudadanos críticos y reflexivos sobre su papel social.

\section{PALABRAS CLAVES}

Violencia; Mujeres; Redes Sociales; Elaine Perez Caparróz.

\section{INTRODUCÇÃO}

A datar de sua popularização no Brasil, nos anos 2000, a internet vem contribuindo, substancialmente, nos modos de pensar e agir dos sujeitos na sociedade da informação. Esta, tem desencadeado significativas alterações na produção da economia, da cultura e nos modos de interação social. Esse indicativo reflete na vida contemporânea, onde as mudanças, desde a modernidade até a contemporaneidade, anunciam transformações no comportamento humano.

$\mathrm{O}$ advento das redes sociais proporcionado pela internet possibilitou a transposição de inúmeras formas de interações interpessoais decorrentes de nossa "vida off-line" para a "vida on-line", além de interferir nos hábitos dos sujeitos, principalmente no que se refere aos processos comunicacionais e no compartilhamento, construção e difusão do conhecimento. Isto é, indivíduos reelaboraram constantemente suas formas de se relacionar com o tempo e o espaço, criando maneiras de socialização em rede.

A interação permitida pelo uso de dispositivos e as potencialidades das tecnologias da comunicação e informação (TIC) tem contribuído para repensar as dinâmicas sociais, de modo que, refletir sobre elas e a inserção das tecnologias digitais em nossa presente sociedade designa em implicá-las nos mecanismos e estratagemas de poder. Nesse ínterim, entende-se que a criminalidade não é um fenômeno alheio a essas transformações. Como a rede é um espaço de socialização como qualquer outro, mediado por ações de indivíduos que fazem parte dela, a violência se anuncia como guisa para a violação dos direitos humanos neste ambiente, mediadas pelas tecnologias digitais.

Assim, este escrito debruça-se em discutir como a violência contra mulheres na rede on-line configura-se como um problema na sociedade brasileira. A expressão dessa problemática demonstra a ausência da palavra, do diálogo e de uma visão crítica, seja por parte de quem a assiste ou de quem a vivencia. Trata-se de um fenômeno multifacetado, que atinge a integridade psíquica, emocional e simbólica de mulheres nas diversas esferas sociais, seja no espaço público ou privado, na "vida on-line" ou "off-line".

O objetivo consiste em explicitar as variadas manifestações odiosas contra as mulheres no Facebook, provocando questionamentos quanto às tensões existentes nas relações dos sujeitos digitais. Para tal, analisar-se-á o caso da empresária de 55 anos, Elaine Caparróz, que foi agredida durante quatro horas em seu apartamento pelo advogado de 27 anos, Vinicius Batista Serra. A idade da vítima e do agressor é explicitada neste escrito em razão dos usuários da rede internet utilizarem a diferença 
geracional entre Caparróz e Serra como argumento para culpabilizar a vítima, além de outras esferas preconceituosas e criminosas que serão analisadas no decorrer do trabalho.

A importância deste texto ratifica-se no reconhecimento da dimensão e dos efeitos que a violência virtual tem implicado, e, no aumento de nosso empenho em constituir um campo de estudo preocupado em identificar seus contornos e abrangência. Além disso, a análise das causas e das relações que geram condutas violentas impõe alguns desafios aos pesquisadores: demanda tanto o reconhecimento das especificidades das situações nesta sociedade em rede, como a compreensão de processos mais abrangentes que produzem a violência. $O$ foco nos discursos de ódio discriminatórios contra as mulheres explica-se no fato de que estas são as maiores vítimas de nossa sociedade patriarcal, estando, desde os primórdios do desenvolvimento da comunidade brasileira, em último lugar na escala social no que se refere a questões salariais, embora, atualmente, sejam mais escolarizadas quando comparadas aos trabalhadores de sexo masculino, são também, estatisticamente, mais atingidas pela violência doméstica. Assim, analisar-se-á os principais fatores que contribuem para os discursos de ódio no ciberespaço que subalterniza a mulher. É nesse cenário que se intui discutir como os usuários da rede se apresentam e como esses fenômenos preconceituosos e violentos se circunscrevem nas redes sociais.

Por fim, apresentar-se-á como resultados desse escrito a dura realidade de afirmar-se e de se tornar mulher em nossa sociedade e como problemas que já eram enfrentados pelos sujeitos femininos na "vida off-line" foram potencializados e reconfigurados na rede on-line, tornando-se um espaço onde as mulheres não estão seguras, visto que esse replica as práticas machistas, fazendo com que estas sejam vítimas dos discursos de ódio que estão ligados a misoginia, crimes de racismo, preconceito, difamação, além de ameaças e injúrias.

\section{ABORDAGEM METODOLÓGICA}

A partir dos pontos supracitados, a proposta apresentada neste artigo tem como base às reflexões que circundam as redes sociais, os processos tecnológicos, suas linguagens e culturas. Os estudos sobre os processos tecnológicos se fundem para dar conta dos enclaves e potencialidades das TIC. O espaço de diálogo criado pelas tecnologias digitais e as (re)socializações evidenciadas pelas redes sociais, mostram a autoria dos sujeitos tecnológicos e, acima de tudo, emerge as percepções dos aspectos antropológicos da sociedade em rede (CASTELLS, 1999).

A abordagem metodológica dar-se-á por meio da análise de conteúdo proposta por Bardin (2011), na qual capturou-se prints com os comentários dos usuários da rede internet em postagens no Facebook sobre o caso em questão e inferiu-se reflexões acerca das intencionalidades ofensivas dos sujeitos em questão. Buscou-se levantar os discursos de ódio direcionados às mulheres na rede. Para além da análise de conteúdo, utilizar-se-á também como aporte metodológico a revisão de cunho bibliográfico, com foco em estudos sobre a temática e categorias abordadas. No decorrer da pesquisa, foram analisados vinte comentários (prints) de três publicações veiculadas na página do Facebook de três grandes jornais nacionais, que perpassam por questões de difamação, injúria, machismo, sexismo, misoginia, preconceito etário e culpabilização da vítima. 
Para tal, dialogamos com algumas (uns) pesquisadoras (es) engajadas (os) nas temáticas e categorias levantadas, Franco (1990), Castells (1999), Bourdieu (2004), Silveira e Pretto (2008), Candau (2008, 2013), Jenkins (2009), Rocha (2012), Miguel e Biroli (2014), Martino (2015), Azevedo (2016), Barsted (2016), Beauvoir (2016), Santos (2016), Hooks (2017, 2019), Ribeiro (2018).

Nesse sentido, entende-se que a educação de base deve ser transformadora, a fim de formar sujeitos pensantes no que tange a vida contemporânea e seu papel social nesta, além de ser aguerrida no que concerne o enfrentamento de preconceitos e discursos discriminatório na vida off-line e na rede internet.

\section{RESULTADOS E DISCUSSÃO: 0 CASO ELAINE CAPARRÓZ}

Na noite do dia 16 de fevereiro de 2019, no bairro da Barra da Tijuca (Zona Oeste da cidade do Rio de Janeiro), a empresária de 55 anos Elaine Caparróz foi agredida em seu apartamento, durante quatro horas, pelo advogado Vinicius Batista Serra, de 27 anos. Segundo a vítima, ela e o agressor interagiam há oito meses nas redes sociais até que ela resolveu convidá-lo para um jantar em sua residência. A vítima foi socorrida pelos vizinhos que ouviram seus gritos de socorro e contataram a polícia. 0 agressor foi preso em flagrante no local do crime.

O caso teve notoriedade e repercussão na grande mídia brasileira, sendo noticiado pelo Fantástico, programa da Rede Globo, dono de uma das maiores audiências da televisão brasileira. Em entrevista, Caparróz contou que dormiu ao lado do agressor e acordou sendo espancada, torturada, xingada e, posteriormente, fora encontrada desacordada, segundo relato dos vizinhos. Diversas páginas nas redes sociais também noticiaram o ocorrido, gerando inúmeras reações dos usuários da rede, foco principal deste escrito.

Figura 1

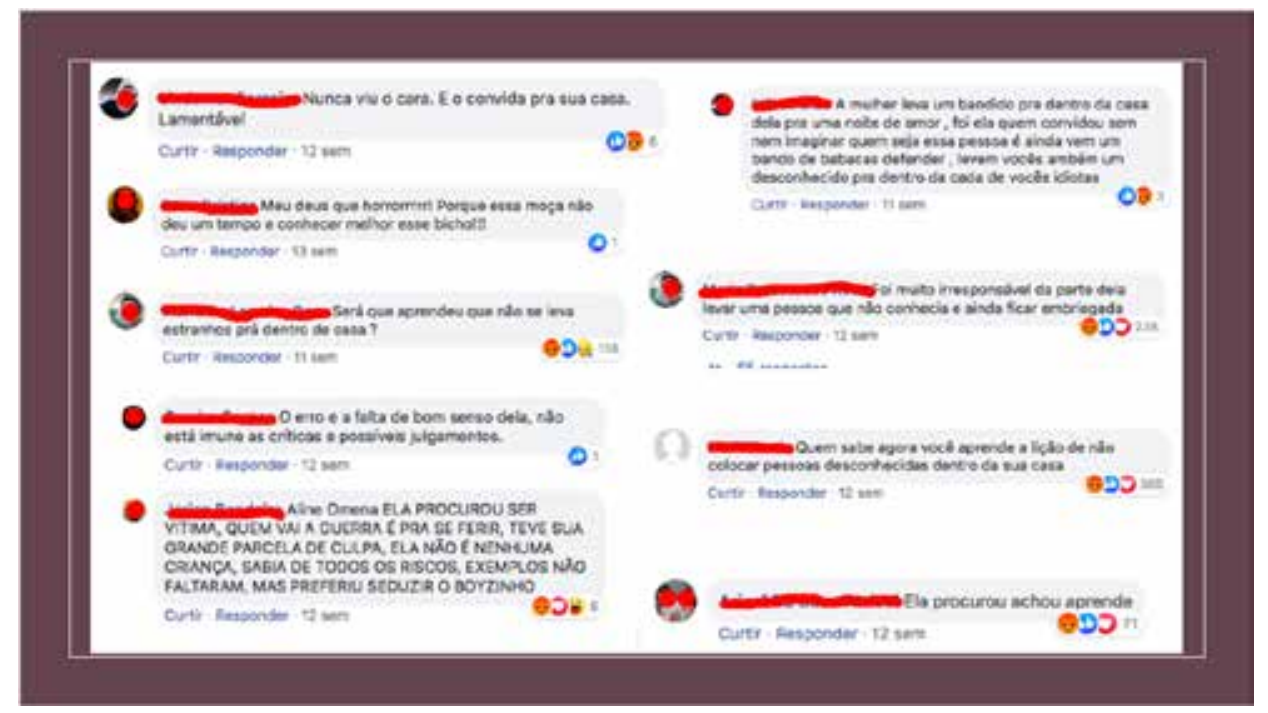


Essa primeira imagem traz à baila os comentários mais recorrentes nas três publicações analisadas que, de forma intencional, "culpabilizam" a vítima pelo crime sofrido. Essa é uma prática que, paulatinamente, tem-se tornado comum na rede internet. Frases como: "quem procura, acha”; "não se leva estranhos para dentro de casa" e "ela procurou ser vítima", demonstram como os usuários da rede concentraram seus julgamentos no comportamento da vítima e não no autor do crime.

0 estupro em que mulheres são vítimas é um crime que, cotidianamente, em nossa sociedade é cercado de interpretações por vezes equivocadas. Para alguns, presume-se que a vítima esteja mentindo. Isto é, a sociedade cobra provas irrefutáveis e, mesmo diante de fatos evidências explícitas, sempre sobram questionamentos, o que não acontece com uma vítima de roubo, por exemplo.

Se a mulher é violentada pelo marido, questiona-se o motivo pelo qual ela escolheu se casar com ele. Se continua casada com o agressor, questiona-se a razão pela qual ela não se separa dele. Se ela se separa dele, questiona-se a capacidade dela em "saber manter" o casamento. Os julgamentos nos quais o agressor nunca é responsabilizado pelos atos que comete são alguns dos principais artifícios da cultura de culpabilizar a vítima.

A cultura de culpabilizar a vítima está enraizada em nossa sociedade machista e patriarcal que acredita existir um comportamento ideal feminino a ser seguido por todas as mulheres.

Para Hooks (2019, p. 95), “A violência patriarcal [...] é baseada na crença de que é aceitável que um indivíduo mais poderoso controle outros por meio de várias formas de forças coercitivas”. Ainda segundo a autora,

0 termo 'violência patriarcal' é útil porque, diferentemente da expressão 'violência doméstica', mais comum, ele constantemente lembra o ouvinte que violência no lar está ligado ao sexismo e ao pensamento sexista, à dominação masculina. (HOOKS, 2019, p. 95).

Nessa conjuntura, a violência contra a mulher se estendeu e se potencializou nas plataformas online, como por exemplo o sexting (prática de enviar mensagens, fotos ou vídeos sexualmente explícitos pelo celular). Segundo a Pesquisa Nacional por Amostra de Domicílios (PNAD), em 2017, o assédio foi o $26^{\circ}$ assunto mais comentado na rede internet; nos últimos três anos, as menções ao termo cresceram $324 \%$, com destaque para o assédio virtual, que registrou crescimento de $26 \mathrm{mil} \%$, demonstrando como a violência virtual e os discursos de ódio vêm afetando a cotidianidade desses sujeitos.

Consoante Butler (apud RIBEIRO, 2018, p. 781),

A linguagem opressora do discurso de ódio não é mera representação de uma ideia odiosa; ela é em si mesma uma conduta violenta, que visa submeter o outro, desconstruindo sua própria condição de sujeito, arrancando-o do seu contexto e colocando-o em outro onde paira a ameaça de uma violência real a ser cometida - uma verdadeira ameaça, por certo. 
Nessa contextura, faz-se necessário entender que esta é uma problemática em que se salienta sua acepção político social, uma vez que “[...] é o resultado das relações de poder, de dominação e de privilégio estabelecidos na sociedade em detrimento das mulheres” (BARSTERD, 2016, p. 17). Isto é, a recorrência da violência contra mulher acaba por ofuscar sua existência no imaginário social, onde acredita-se que o problema foi solucionado com a criação da Lei Maria da Penha (Lei n 11.340/06) e, posteriormente, a Lei do Feminicídio (Lei nº 13.104/2015).

A demanda política também se agrava no tocante a representatividade feminina na política. Findada as últimas eleições brasileiras (2018), constatou-se que as mulheres ocuparam apenas 15\% do novo congresso (segundo notícia divulgada pelo Tribunal Superior Eleitoral, em março de 2019), mesmo após a sanção da Lei no 13.165, de 2015, que, em seu Art. 10, diz:

$\S 30$ Do número de vagas resultante das regras previstas neste artigo, cada partido ou coligação preencherá o mínimo de 30\% (trinta por cento) e o máximo de 70\% (setenta por cento) para candidaturas de cada sexo. (BRASIL, 2015)

A representatividade política é majoritariamente ocupada por homens, situação que foi desenvolvida historicamente. Logo, a mulher que conseguir adentrar esse território estará imersa em um ambiente machista, sexista e misógino; destarte, ela não será discriminada porque é diferente, ela se tornará diferente por ter a necessidade de enfrentar a discriminação e a desigualdade de gênero.

Essa é uma problemática que tem fundamento histórico. Em território nacional, somente em meados do século XIX as mulheres puderam estudar em instituições de ensino básico e superior; e apenas em 1932 venceram a luta pelo direito ao voto.

Nas relações profissionais, a desigualdade de gênero também é notória. De acordo com o estudo de Estatísticas de Gênero, divulgado esse ano pelo Instituto Brasileiro de Geografia e Estatística (IBGE), as mulheres trabalham, em média, três horas por semana a mais do que os homens, combinando trabalhos remunerados, afazeres domésticos e cuidados de pessoas e, mesmo assim, contando com um nível educacional mais alto, ganham, em média, $76,5 \%$ do rendimento dos homens, por vezes ocupando os mesmos cargos.

Desse modo, embora a nossa atual Constituição Federal afirme, em seu artigo $5^{\circ}$, que homens e mulheres são iguais perante as leis, a norma não garante, necessariamente, a efetividade da legislação e a qualidade de vida das cidadãs brasileiras.

Toda essa discussão é necessária no âmbito da violência virtual e do discurso de ódio contra mulheres, posto que estas precisam ocupar esses espaços de poder na política, a fim de pensarem projetos para o enfrentamento e prevenção das práticas violentas em rede; e, maiormente, deixarem de ser os sujeitos por quem se fala e assumiram o seu lugar de fala. 
Figura 2

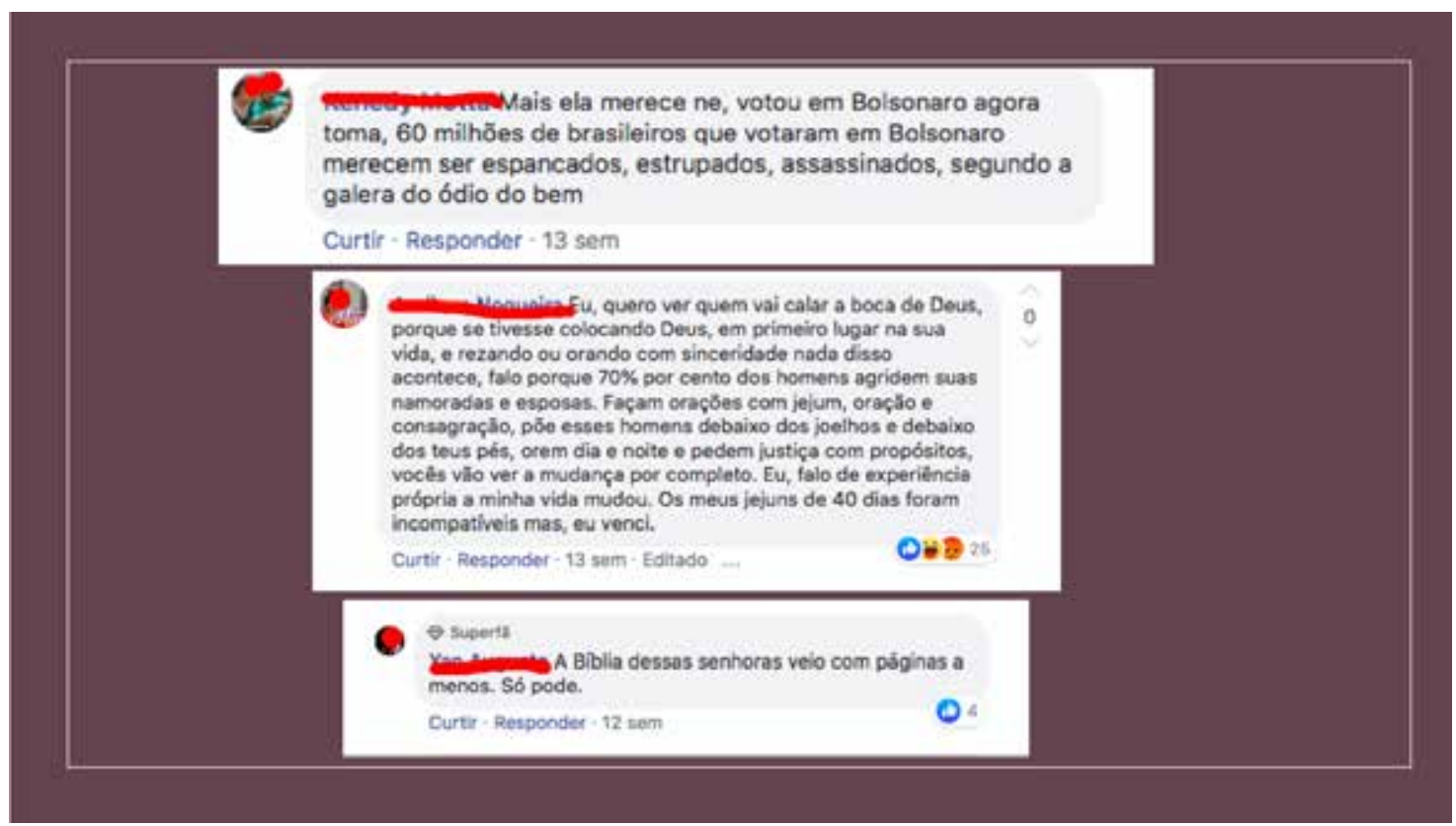

$\mathrm{Na}$ imagem dois percebe-se que os usuários tentam justificar a agressão sob dois vieses: o posicionamento político da vítima e seu suposto afastamento da religião. Referindo-se ao viés religioso, o usuário afirma que o crime só ocorreu em razão de um suposto afastamento da vítima da bíblia; diz suposto, pois em momento algum Caparróz afirmou não ser religiosa ou não possuir religião. Isso concerne falta de respeito ao direito de outrem possuir ou não religião, ferindo, inclusive, a concepção religiosa do "livre arbítrio", no qual o ser humano é livre para decidir o melhor caminho para gerir sua vida.

Nota-se, também, que o usuário atribui somente a mulher o papel de se esforçar para manter o casamento, quando diz "se tivesse colocado Deus, em primeiro lugar na sua vida, e rezando ou orando com sinceridade nada disso acontece, falo porque $70 \%$ dos homens agridem suas namoradas e esposas. Façam orações com jejum, oração e consagração, pões esses homens debaixo dos joelhos e debaixo dos seus pés, orem dia e noite."

Esta afirmação ratifica a cultura machista e patriarcal que inferioriza as mulheres na sociedade, como corrobora Ribeiro (2018, p. 911), “[...] machismo e racismo são elementos estruturantes desta sociedade, de modo que nenhum espaço estará isento dessas opressões”. Trazendo as concepções Beauvoir (2016) para pensarmos a realidade brasileira, nota-se que diversas propagandas celebram e bendizem mulheres que conseguem assumir diversas atividades e mesmo assim "manter um sorriso no rosto". Elas trabalham, cuidam sozinhas do cotidiano de suas casas e dos filhos. Elucidar essas questões é um passo para chamar a atenção do Estado e da sociedade sobre a desigualdade de gênero. 
O posicionamento político da vítima também foi utilizado para justificar a agressão. 0 fato de Caparróz apoiar o atual líder do Poder Executivo brasileiro deu margem para os usuários da rede considerarem merecida a violência sofrida por ela. Essa é uma situação que demonstra a ausência de diálogo e respeito em relação ao pluralismo de ideias que deve sempre prevalecer em uma sociedade democrática.

0 exercício da liberdade é fundamental para a preservação de uma democracia. Nessa estruturação política, faz-se imprescindível a liberdade de associação, de pensamento e de expressão, no qual não devem existir distinções ou privilégios de classe hereditários ou arbitrários.

O ensino escolar básico é de suma importância para a efetivação do pluralismo de ideias na sociedade. As instituições de ensino (junto à família e organização social), são responsáveis pelo desenvolvimento intelectual e cidadão dos sujeitos que estão em formação e, para isso, é necessário subsidiar aos educandos uma educação que englobe uma diversidade de ideias presentes na história e na cotidianidade social, nunca colocando uma ideologia em detrimento da outra; cabendo apenas ao discente escolher que caminho ideológico seguir.

Destarte, evitar-se-á a efetivação da “educação bancária” (FREIRE, 2017, p. 79), concebida pelo patrono da educação brasileira, Paulo Freire, que critica o modelo mecânico de ensino-aprendizagem, no qual o educador coloca-se como o detentor do conhecimento e o deposita nos educandos como se estes fossem recipientes a serem preenchidos.

Assim, entende-se a importância de os educadores firmarem relações flexíveis com os discentes em todo o ambiente escolar, sabendo que todos ali presentes têm conhecimento a ser mediado, pois num processo de ensino-aprendizagem todos ensinam e todos aprendem.

Figura 3

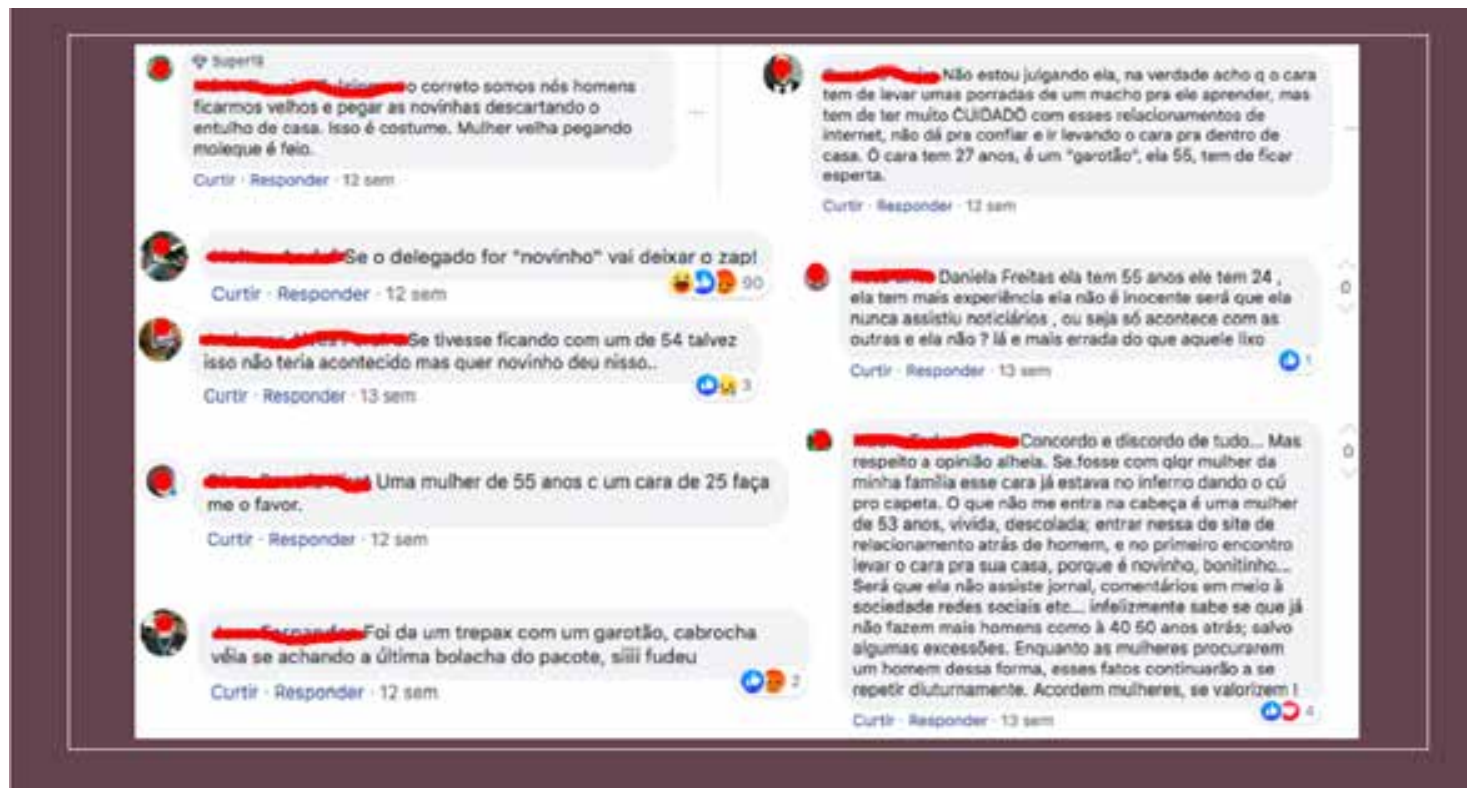


Figura 4

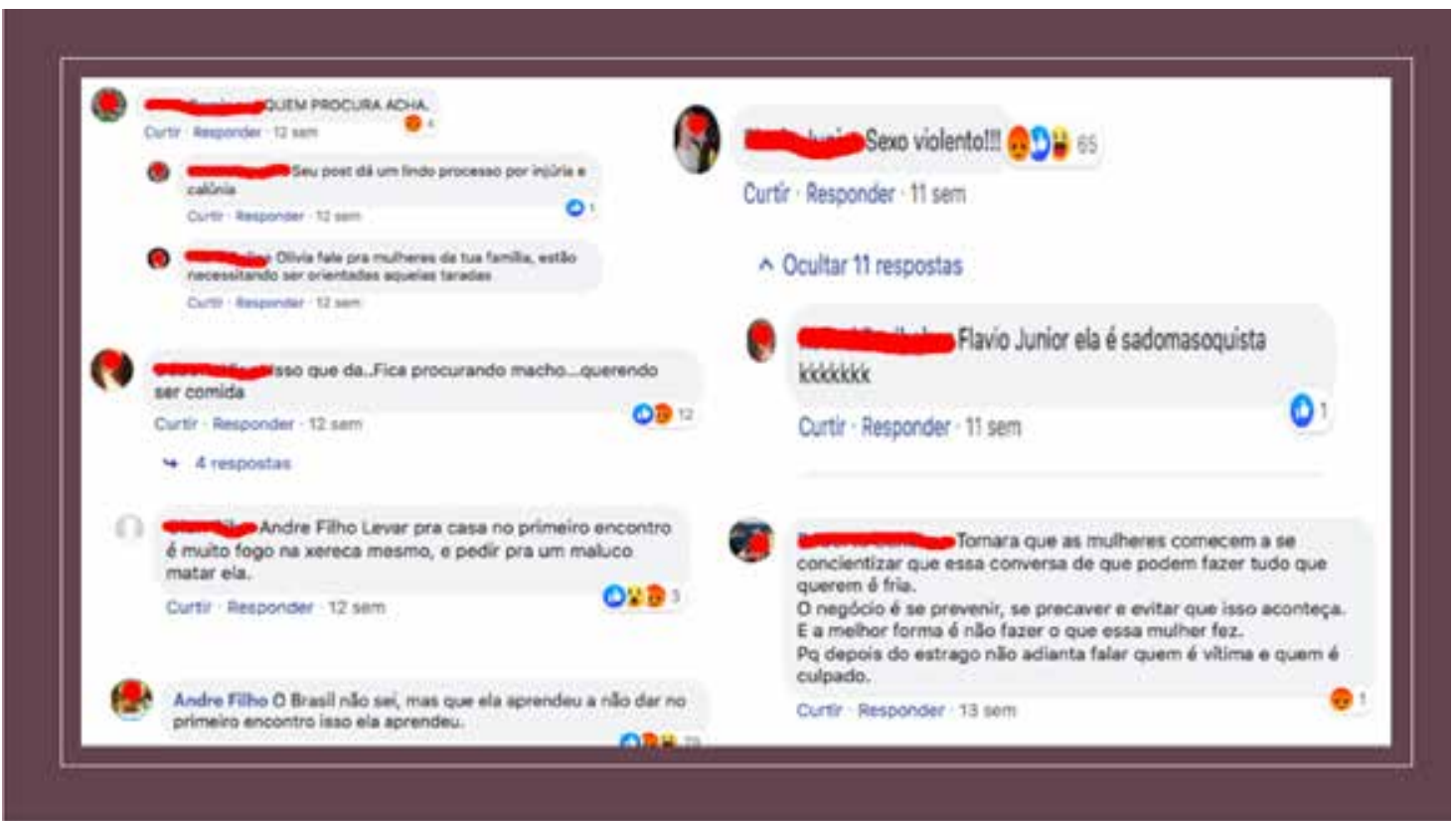

Nas imagens três e quatro, temos comentários de preconceito etário. Neles, os usuários "culpabilizam" a vítima pelo fato dela ter se envolvido com uma pessoa quase trinta anos mais jovem. Da maneira como pensa Bourdieu (2004, p. 118), é expressivamente demasiada a desvalorização com os idosos, dado que “[...] a velhice é um declínio social, uma perda de poder social”.

A Organização Mundial da Saúde (OMS) realizou em 2016 a "Pesquisa dos Valores Mundiais”, com 83 mil pessoas de 57 países diferentes. Nela, $60 \%$ dos entrevistados acreditam que os idosos não são respeitados. No que concerne a mulher idosa, as dificuldades são maiores, visto que estas, além de enfrentarem a discriminação etária, ainda sofrem as interiorizações impostas pelo machismo, sexismo e patriarcado. Sobre o assunto, Azevedo (2016, p. 274) afirma que:

[...] a sobrecarga de tarefas impostas às mulheres, tradicionais cuidadoras, afetando seu equilíbrio emocional, bem como a ausência de políticas públicas que auxiliem e atuem como facilitadoras das relações domésticas, se constituem em outros tantos fatores que favorecem as relações de violência.

Essas relações de violência são abarcadas nas esferas social, econômica, cultural e política, não sendo possível indicar uma única esfera como causadora das manifestações violentas.

A vista disso entende-se que um dos motores da violência é a satisfação dos impulsos e desejos destrutivos do ser humano. Esses motivos são geralmente racionalizados (de acordo com as subjetivi- 
dades do agressor), e busca justificar, perante a consciência, a existência dessa destrutividade. Além disso, a estrutura social classista ajuda na perpetuação das práticas violentas na sociedade.

Nesse sentido, Rocha (2015, p. 23) afirma que,

[...] o Estado violentador põe-se como agente da opressão quando perpetua uma estrutura de classes desigual. Aqui, a violência é entendida como estrutural (opressão exercida pelos sistemas econômico, político e social, e pelas instituições em geral sobre grupos, classes, nações, indivíduos).

Compreende-se, então, que a violência pode ser expressa e sofrida em diversas esferas internas e externas aos sujeitos, podendo ser um produto da natureza, no sentido de que é intrínseca à humanidade; e, para outros, um produto da história, que não é, portanto, natural ao homem. Ela se manifesta como produção e linguagem estética, como forma de ser, de se comunicar, de vivenciar, de apreender e interpretar o mundo.

Assim, mesmo a rede on-line sendo fomentadora no que tange a projeção de conhecimento dos indivíduos, também é um ambiente "[...] fértil para a ampliação de aspectos conflituosos de realidade palpável e do relacionamento social, como o ódio e todas suas manifestações” (SANTOS, 2016, p. 8).

Para mais, também na imagem três têm-se comentários que se caracterizam como injúria e difamação, a exemplo das afirmações "ela é sadomasoquista", "fica procurando macho, querendo ser comida" e "levar para casa no primeiro encontro é muito fogo na xereca mesmo, é pedir pra um maluco matar ela”. A legislação está descrita no Art. 40 do Código Penal - Decreto Lei 2848/40, que diz,

Injuriar alguém, ofendendo-lhe a dignidade ou o decoro:

Pena - detenção, de um a seis meses, ou multa.

$\S \mathbf{2}^{\mathbf{0}}$ - Se a injúria consiste em violência ou vias de fato, que, por sua natureza ou pelo meio empregado, se considerem aviltantes:

Pena - detenção, de três meses a um ano, e multa, além da pena correspondente à violência.

§ $3^{\circ}$ - Se a injúria consiste na utilização de elementos referentes a raça, cor, etnia, religião, origem ou a condição de pessoa idosa ou portadora de deficiência: (Redação dada pela Lei $n^{0} 10.741$, de 2003)

Pena - reclusão de um a três anos e multa. (Incluído pela Lei nº 9.459, de 1997) (BRASIL, 1940)

Quando um menino nasce, é comum no Brasil que ele seja socializado como um homem cisgênero e heterossexual. Recebe direcionamentos de como um homem deve se comportar na sociedade por meio de programas de televisão, do ambiente virtual, de brinquedos e pelos pais em seu leito familiar. O homem é instruído a ser valente, corajoso, "mulherengo", forte, "pegador" e apático às questões femininas.

A menina contrapondo isso, aprende a ser recatada, delicada, educada, gentil, pura e bonita, beleza esta que tem todo um padrão de peso, alisamento dos cabelos, remoção dos pelos, vestuário adequado e outras searas. A raiz do problema está exatamente nos violentos processos culturais que 
cultivam a hegemonia do homem opressor e a submissão da mulher, ratificados pelo (mau) uso das redes sociais, que corroboram preconceitos presentes em nossa vida off-line. Dados divulgados pela ONG SaferNet, que atua na defesa dos direitos humanos em ambientes virtuais em parceria com o Ministério Público Federal, apontaram que as denúncias de crimes ligados à violência contra a mulher tiveram uma explosão em 2018 quando comparadas ao ano anterior: em 2017, foram registradas 961 denúncias desse tipo, contra 16.717 em 2018, um crescimento de $1.640 \%$. Essas violências perpassam por crimes como assédio sexual, ameaças contra a vida, calúnia e difamação, chantagem, racismo, a chamada "vingança pornô", além do machismo e da misoginia. A série de problemas agrava-se ainda mais quando se entende que as mulheres são alvos dos crimes citados alhures apenas pelo fato de serem mulheres.

Discursos de ódio e discriminatórios relacionados ao gênero, sexualidade, classe social, posicionamento político e religioso, cor, raça e etnia são uma realidade na rede internet; estes, podem ser caracterizados por qualquer expressão que desvalorize, oprima e desqualifique os sujeitos. Trata-se de uma situação de desrespeito social e moral, visto que reduz o ser humano à condição de objeto. Identificar e caracterizar os discursos de ódio não é uma tarefa simples, pois estes podem aparecer de forma implícita ou explícita; isto é, a intenção violenta do agressor pode aparecer de maneira clara e objetiva ou subliminar.

Sobre violência, Franco (1990) define como “[...] um processo dirigido a certos fins, tendo diferentes causas, assumindo formas variadas e produzindo certos danos, alterações e consequências imediatas ou a longo prazo". Essa definição nos permite pensar que a violência precisa ser interpretada e definida em suas várias faces, no mundo off-line ou on-line e por meio dos eventos em que se expressa, se repercute e se reproduz por meio da linguagem e do espaço em que é professado.

Costa (1984, p. 30) define violência como “O emprego desejado da agressividade, com fins destrutivos. Esse desejo pode ser voluntário, deliberado, racional e consciente, ou pode ser inconsciente, involuntário e irracional".

Rocha (2012, p. 87), afirma que "[...] A possibilidade de anonimato na internet é o elemento que encoraja as atitudes agressivas". Consoante ela, Martino (2015, p. 31) nos diz que "[...] o mundo virtual existe enquanto possibilidade, e se torna visível quando acessado, o que não significa que ele não seja real".

Em outros termos, por oferecer a ilusão do suposto anonimato e por tornar-se um ambiente de rápida veiculação de mensagens com um grande alcance de público, esses crimes que já eram executados na vida off-line foram transferidos para a vida on-line. Destarte, os ativos digitais estão "[...] em constante encontro com a alteridade" (SANTOS, 2016, p. 54) e esse encontro tem se manifestado, por vezes, criminoso, odioso e violento dentro das redes sociais.

Nesse sentido, a violência ocorre quando há desejos de destruição da parte do algoz. Caracteriza-se pela intencionalidade e está presente em toda ação humana. Recuperando Costa (1984, p. 47), a violência institui-se a partir dos conflitos instaurados no âmbito da cultura e a entende "[...] como uma particularidade do viver social, um tipo de negociação, que, através do emprego da força ou da agressividade, visa a encontrar soluções para conflitos que não se deixam resolver pelo diálogo e pela cooperação". 
Assim, entende-se que não existe apenas uma percepção do que seja violência, mas multiplicidade de atos violentos, cujas significações devem ser analisadas a partir das normas, das condições e dos contextos sociais e, referindo-se as mulheres na contemporaneidade, sempre considerando a raça, classe e gênero.

Face ao exposto, é indispensável notabilizar que o melhor caminho para prevenir e debelar a violência contra mulheres na rede internet está na criação e aplicação de políticas públicas e em práticas educativas escolares; e o debate sobre a continuidade da dominação masculina e do patriarcado nos tempos hodiernos abriu portas para elucidar, questionar, refletir e “[...] complexificar as categorias centrais por meio das quais era pensado o universo da política, tais como as noções de indivíduo, de espaço público, de autonomia, de igualdade, de justiça ou de democracia” (MIGUEL; BIROLI, 2014, p. 17).

Como política e educação não se dissociam, Miguel e Biroli (2014, p.14), também afirmam que “[...] a demanda por educação tem por objetivo exclusivo permitir o livre desenvolvimento da mulher como ser racional, fortalecendo a virtude por meio do exercício da razão e tornando-a plenamente independente”. Além disso, as práticas educativas dentro do espaço escolar devem estar atentas ao uso da rede internet, a diversidade social, ao multiculturalismo, a liberdade de expressão e de escolha e a libertação das amarras que subalternizam a mulher. Isto posto, Bell Hoocks (2017, p. 25) declara que

A educação como prática da liberdade é um jeito de ensinar que qualquer um pode aprender. Esse processo de aprendizado é mais fácil para aqueles professores que também creem que sua vocação tem o aspecto sagrado; que creem que nosso trabalho não é o de simplesmente partilhar informação, mas sim o de participar do crescimento intelectual e espiritual dos nossos alunos. Ensinar de um jeito que respeite e proteja as almas de nossos alunos é essencial para criar as condições necessárias para que o aprendizado possa começar do modo mais profundo e mais íntimo.

\section{CONSIDERAÇÕES FINAIS}

As reflexões do escrito, acima apresentado, giraram em torno da evolução dos processos tecnológicos e como estes fomentaram os discursos de ódio contra mulheres nas redes sociais digitais. Regras de comportamento ideal feminino, heteronormatividade, atitudes e preconceitos vorazes contra uma parcela da população que não se encaixa nos modelos e padrões estabelecidos como "corretos" da organização social, impulsionam ofensas, estratégias de poder e dominação do sexo masculino ao feminino.

Nesse sentido, é importante salientar que o avanço tecnológico e o acesso a internet não devem ser responsabilizados pelo mal que acontece no ciberespaço, pois, atrás de um computador ou smartphone tem um operador humano que manipula as interações. Além disso, é fundamental que educadores se apropriem mais sobre tecnologias, conhecendo as possibilidades de seu uso. Por outro lado, não se pode e nem se deve privar crianças e adolescentes do uso das tecnologias digitais, mas tem-se a obrigação de ensiná-los a navegar na rede de maneira segura.

Os crimes relacionados ao ódio, na esfera off-line e on-line, se transformaram numa questão estatal e sua repreensão reflete a preocupação quanto a influência desse fenômeno na vida social das coletividades. 
Assim, não se pode considerar os indivíduos como totalmente iguais e situados num espaço tempo fixo, uma vez que o respeito à condição humana aponta para a diversidade da própria condição humana. Entretanto, entende-se a importância e necessidade de homens e mulheres cumprirem e terem direitos as mesmas leis, terem as mesmas oportunidades de trabalho, formação acadêmica e respeitar uns aos outros, independentemente de suas raças, crenças, ideais e valores.

Ademais, o discurso do ódio e a violência virtual contra a mulher se voltam contra a diversidade humana, fere a atual Constituição Federal e, sobretudo, compromete a segurança na internet.

\section{REFERÊNCIAS}

AZEVEDO, Eulália Lima. Violência de gênero na trama geracional. In: SARDENBERG, Cecilia M. B.; TAVARES, Márcia S. (Org.). Violência de gênero contra mulheres: suas diferentes faces e estratégias de enfrentamento e monitoramento. Salvador: EDUFBA, 2016.

BARSTED, Lelia Linhares. O feminismo e o enfrentamento da violência contra as mulheres no Brasil. In:SARDENBERG, Cecilia M. B.; TAVARES, Márcia S. (Org.). Violência de gênero contra mulheres: suas diferentes faces e estratégias de enfrentamento e monitoramento. Salvador: EDUFBA, 2016.

BOURDIEU, Pierre. Campo de poder, campo intelectual. BA: Quadrata, 2004.

BRASIL. Constituição Federal de 1988. Promulgada em 5 de outubro de 1988. Disponível em: http://www.planalto.gov.br/ccivil_03/constituicao/constituição.htm. Acesso em: 11 jul. 2019.

BRASIL. Decreto-Lei 2.848, de 07 de dezembro de 1940. Código Penal. Diário Oficial da União, 2015.

COSTA, J. F. Violência e psicanálise. Rio de Janeiro: Graal, 1999.

FRANCO, S. La violência: un problema de salud pública que se agrava en la Región. Boletín Epidemiológico de la OPS, v. 11, n. 2, p. 1-7, 1990.

FREIRE, Paulo. Pedagogia do oprimido. São Paulo: Paz \& Terra, 2017.

HOOKS, Bell. Ensinando a transgredir: a educação como prática da liberdade. São Paulo: WMF Martins Fontes, 2017.

HOOKS, Bell. 0 feminismo é para todo mundo: políticas arrebatadoras. São Paulo: Rosa dos Tempos, 2019. 
IBGE - Instituto Brasileiro de Geografia e Estatística. Estudo sobre Estatísticas de Gênero 2018. Disponível em: https://biblioteca.ibge.gov.br/visualizacao/livros/liv101551_informativo.pdf. Acesso em: 11 jul. 2019.

JENKINS, Henry.Cultura da convergência. São Paulo: Aleph, 2009.

MARTINO, Luis Mauro Sa. Teorias das mídias digitais. Linguagens, ambientes e redes. Petropólis: Vozes, 2015.

MIGUEL, Luis Felipe; BIROLI, Flávia. Feminismo e política. São Paulo: Boitempo, 2014.

OMS - Organização Mundial da Saúde. Pesquisa dos Valores Mundiais. 2016. Disponível em: https://www.who.int/eportuguese/publications/pt/. Acesso em: 27 maio 2019.

RIBEIRO, Djamila. Quem tem medo do feminismo negro? São Paulo: Cia das Letras, 2018.

ROCHA, Telma Brito. Cyberbullying: ódio, violência virtual e profissão docente. Brasília: Liber Livro, 2012.

ROCHA, Telma Brito. Violência, Agressividade e Poder: conceitos para professores compreenderem conflitos no ambiente escolar. In: WANZINACK, Clovis;

SIGNORELLI, Marcos Claudio (Org.). Violencia, genero e diversidade: desafios para a educação e o desenvolvimento. Rio de Janeiro: Autografia, 2015.

SANTOS, Marco Aurélio Moura dos. 0 discurso de ódio nas redes sociais. São Paulo: Lura Editorial, 2016. 
Recebido em: 30 de Outubro de 2019

Avaliado em: 5 de Novembro de 2019

Aceito em: 10 de Novembro de 2019

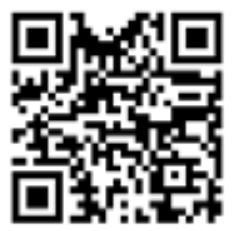

A autenticidade desse artigo pode ser conferida no site https://periodicos.set.edu.br

1 Professora da Faculdade de Educação da Universidade Federal da Bahia - FACED/UFBA. E-mail: telmabr@gmail.com

2 Acadêmico em Licenciatura em Pedagogia - FACED/UFBA; Bolsista PIBIC-UFBA. E-mail: cleytonya26@gmail.com

\section{(2) (1) (2)}

Este artigo é licenciado na modalidade acesso abertosob a Atribuição-Compartilha Igual CC BY-SA

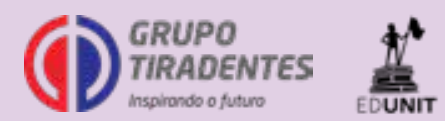

